\section{Research Square}

Preprints are preliminary reports that have not undergone peer review.

They should not be considered conclusive, used to inform clinical practice, or referenced by the media as validated information.

\title{
Gender differences in the relationship between dietary energy and macronutrients intake and body weight outcomes in Chinese adults
}

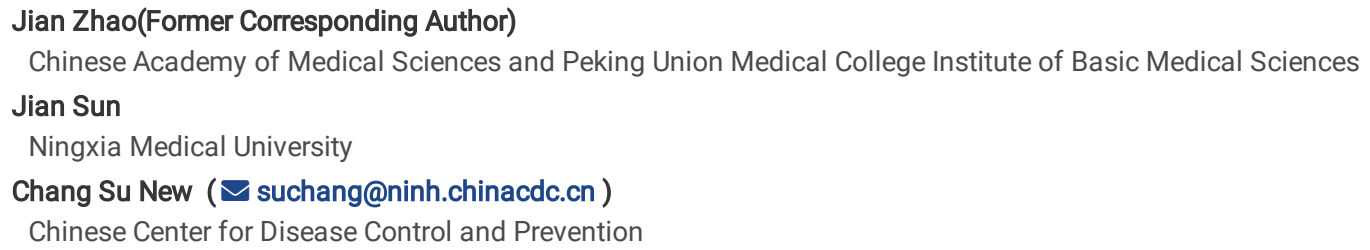

\section{Research}

Keywords: Nutritional Assessment, Macronutrient, Obesity, Gender

Posted Date: April 8th, 2020

DOI: https://doi.org/10.21203/rs.2.19272/v2

License: (c) (1) This work is licensed under a Creative Commons Attribution 4.0 International License. Read Full License

Version of Record: A version of this preprint was published at Nutrition Journal on May 18th, 2020. See the published version at https://doi.org/10.1186/s12937-020-00564-6. 


\section{Abstract}

Background To explore the the gender differences in the relationship between dietary energy and macronutrients intake and body weight outcomes in Chinese adults.

Methods Data from the China Health and Nutrition Survey (CHNS, 2015) for10,898 participants aged 18-64 years. Three consecutive 24-h dietary recalls was used to assess the dietary intake. Quantile regression models for body mass index (BMI) and waist circumference (WC) were performed separately for each sex.

Results Adult males showed greater absolute intakes of energy and macronutrients as compared to females as per the body weight outcomes. A $10 \%$ increase in BMl resulted in an additional intake of $0.002-0.004 \mathrm{kcal} / \mathrm{d}$ of dietary energy, $0.032-0.057 \mathrm{~g} / \mathrm{d}$ of fats, $0.039-0.084 \mathrm{~g} / \mathrm{d}$ of proteins, and $0.018-0.028$ $\mathrm{g} / \mathrm{d}$ of carbohydrates across all quantiles in males $(\mathrm{p}<0.05)$. A $10 \%$ increase in WC resulted in an additional intake of $0.004-0.008 \mathrm{kcal} / \mathrm{d}$ of dietary energy, $0.051-0.052 \mathrm{~g} / \mathrm{d}$ of carbohydrates across the entire quantile in males $(\mathrm{p}<0.05)$, and an increased intake of $0.060-0.150 \mathrm{kcal} / \mathrm{d}$ of fat in females $(\mathrm{p}<0.05)$.

Conclusions Dietary Fat intake could be the risk factor of abdominal obesity in women. The importance of gender-specific evidence should be considered before promoting macronutrient allocation for the prevention and treatment of obesity.

\section{Introduction}

Imbalanced dietary energy and macronutrient intake is associated with weight gain and increased risk of chronic non-communicable diseases that kills approximately 3 million people worldwide each year [1, 2]. According to the Chinese Residents Nutrition and Chronic Disease Status Report, the obesity rates of Chinese adults aged 18 and above increased from $4.8 \%$ in 2002 to $11.9 \%$ in 2015 [3]. Identifying effective solutions to prevent further weight gain has received attention, as it is a major public health concern in the light of the obesity epidemic in China.

Dietary energy is primarily provided by macronutrients including fats, carbohydrates, and proteins, and the cause of weight gain is energy imbalance[4]. Several preliminary studies suggested that the macronutrient composition in the diet plays an important contributory role in obesity [5, 6]. However, the role of individual macronutrients in the development of obesity remains controversial[7]. Understanding the usual intake of dietary energy and macronutrients is essential for estimating appropriate dietary intake and nutritional interventions[8]. Body mass index (BMI) and waist circumstance (WC) are the commonly used parameters to assess general and abdominal adiposity in clinical practice[9]. A few studies have been conducted on energy intake and assessment of the percentage contribution of macronutrients in Brazil, Iranian, Japan, United Kingdom, and United States[10, 11], but to some extent have lacked a comprehensive information linking dietary energy and specific macronutrients directly to general and abdominal obesity in the largest developing country, China. Additionally, sex disparities should not be overlooked in studies of overweight and obesity along with differences in physiological and lifestyle factors[12].

Using updated data from the China Health and Nutrition Survey (CHNS, 2015), the current study aimed to provide a detailed description of the sex-related distribution of dietary energy and macronutrient intake, and further investigate the possible relationship between BMI and WC with energy and the percentage of energy intake from macronutrients among Chinese adults.

\section{Materials And Methods}

\section{Study design and subjects}

We used data of the CHNS(2015) for the present investigation, which is a large-scale, longitudinal, household-based survey initiated in 1989 that consists of representative participants of varying economic status, health indicators, and geographic areas throughout China[13]. A multistage, random cluster sample was used in the study[14]. Further information on survey procedures and the sampling scheme is reported in detail elsewhere[15]. We excluded participants who were pregnant or lactating or who reported implausible energy intakes $(<800 \mathrm{kcal} / \mathrm{d}$ or $>6000 \mathrm{kcal} / \mathrm{d}$ for males and $<600 \mathrm{kcal} / \mathrm{d}$ or $>4000 \mathrm{kcal} / \mathrm{d}$ for females). Hence, our final sample consisted of 10,898 observations (4,934 males and 5,964 females) aged 18-64 years with complete demographic data and information on socioeconomic status and 3-day, $24 \mathrm{~h}$ dietary recalls in a survey year.

\section{Dietary data}

Well-trained interviewers asked all participants by a semi-quantitative food frequency questionnaire (FFQ) for dietary assessment. We used three consecutive 24-h dietary recalls to assess the individual levels of total energy intake [16]. We calculated the percentage of fats, carbohydrates, and proteins in the daily energy intake based on the Chinese Food Composition Table to represent the dietary structure[17]. Energy levels and macronutrient deficiencies or surpluses in the sample and age-sex subgroup were also assessed based on appropriate dietary reference intakes (DRIs)[11].

\section{Anthropometrics and obesity indicators}

Well-trained health workers measured the height (model 206, SECA), weight (model 880, SECA), and WC of participants following standardized procedures. We calculated BMI by dividing the weight (in $\mathrm{kg}$ ) by the square of the height (in $\left.\mathrm{m}^{2}\right)$. We grouped the BMI into thin $\left(<18.5 \mathrm{~kg} / \mathrm{m}^{2}\right), \mathrm{normal}\left(18.5-23.9 \mathrm{~kg} / \mathrm{m}^{2}\right)$, overweight $\left(24-27.9 \mathrm{~kg} / \mathrm{m}^{2}\right)$, and obesity $\left(>28 \mathrm{~kg} / \mathrm{m}^{2}\right)$, based on the recommended cut-off points of BMl for overweight and obesity in Chinese adults by the Working Group on Obesity in China[18]. We measured WC from the midpoint between the lower border of the rib cage and the iliac crest to the nearest $0.1 \mathrm{~cm}$ using a SECA tape. We defined participants as having abdominal obesity if the WC $\geq 85 \mathrm{~cm}$ in females and $\geq 90 \mathrm{~cm}$ in males in accordance with the guideline of the National Health and Family Commission for Chinese Adults (2013)[19]. 


\section{Other relevant variables}

We grouped participants into two age groups (18-44 and 45-64 years), two marital statuses (single and married), three education level (primary/illiterate, middle, and high school/above), two geographical regions (rural and urban), and three income levels (low, medium, and high). We classified the smoking status as current or ever/never and drinking status as current or non/ever. Physical activity (PA) included four domains: occupational, household chore, leisure time, and transportation activities. Participants reported all PAs in average hours per week, and we converted the time spent in each activity into a metabolic equivalent of task (MET) hours per week based on the Compendium of Physical Activities. We grouped the total MET hours per week into low, middle, and high [20].

\section{Statistical analysis}

Statistical analyses were performed with SAS 9.4 (SAS Institute, Inc. Cary, NC, USA). The values were reported as mean and standard errors for continuous variables or as proportions of the total for categorical variables. Descriptive statistics for sample characteristics were presented as weighted mean or weighted percentage. The F-test (continuous variables) and adjusted Pearson chi-square tests (categorical variables) were used to determine sex-based differences in the distribution of dietary intake with basic characteristic and body weight outcomes. Using the PROC QUANTREG procedure, series quantile regression models for continuous BMI and WC measurements in males and females were conducted to explore the associations between energy intake and macronutrients composition for general and abdominal obesity in China. Two models were tested that included an unadjusted model (model 1 ) and an adjusted model (model 2), where the latter controlled for additional individual variables including age, education level, income level, geographic region, physical activity, drinking, and smoking.

\section{Results}

\section{Basic characteristics of the study population}

Descriptive differences of basic characteristics of the participants were presented in Table 1. Of the 10,898 adult participants, 4,934(45.3\%) were males and 5,964(54.7\%) were females. The average BMI and WC was $24.4 \mathrm{~kg} / \mathrm{m}^{2}$ and $82.6 \mathrm{~cm}$ in males, $24.0 \mathrm{~kg} / \mathrm{m}^{2}$ and $81.0 \mathrm{~cm}$ in females, respectively. The intake of dietary energy, fats, proteins, and carbohydrates was $2273.9 \mathrm{kcal} / \mathrm{d}, 91.5 \mathrm{~g} / \mathrm{d}, 74.0$ $\mathrm{g} / \mathrm{d}$, and $282.4 \mathrm{~g} / \mathrm{d}$ in males, and $1919.4 \mathrm{kcal} / \mathrm{d}, 77.7 \mathrm{~g} / \mathrm{d}, 62.3 \mathrm{~g} / \mathrm{d}$, and $242.0 \mathrm{~g} / \mathrm{d}$ in females, respectively. Some variables were observed to have statistically significant differences between the sexes, such as age, income, smoking, drinking, energy and macronutrients intake $(\mathrm{p}<0.001)$. Males consumed more dietary energy, fats, proteins, carbohydrates than females $(\mathrm{p}<0.001)$. In addition, males had higher BMI and WC than females $(\mathrm{p}<0.001)$.

$<$ Table $1>$ Demographic characteristics of the sample 
Table 1. Baseline characteristics of the study population in CHNS(2015) by genders ${ }^{1,2}$

\begin{tabular}{|c|c|c|c|}
\hline General Characteristic & Female $(\mathbf{N}=5,964)$ & $\operatorname{Men}(\mathrm{N}=4,934)$ & $p$-Value \\
\hline Age, $n(\%)$ & & & $<0.001$ \\
\hline $18-44$ years & 2318(38.9) & 1753(35.5) & \\
\hline 45-64 years & $3646(61.1)$ & $3181(64.5)$ & \\
\hline Education,$n(\%)$ & & & $<0.001$ \\
\hline Primary/illiterate & 1752(29.4) & 933(18.9) & \\
\hline Middle school & $2122(35.6)$ & 1929(39.1) & \\
\hline High/above & $2090(35.0)$ & $2072(42.0)$ & \\
\hline Income, $n(\%)$ & & & 0.005 \\
\hline Low & 1883(31.6) & $1429(29.0)$ & \\
\hline Medium & 1963(32.9) & $1630(33.0)$ & \\
\hline High & 2118(35.5) & 1875(38.0) & \\
\hline Geogerphical region, $n(\%)$ & & & 0.437 \\
\hline Rural & $3727(62.5)$ & $3119(63.2)$ & \\
\hline Urban & 2237(37.5) & $1815(36.8)$ & \\
\hline PA level, $n(\%)$ & & & $<0.001$ \\
\hline Low & 1923(32.2) & 1708(34.6) & \\
\hline Medium & 2108(35.3) & 1536(31.1) & \\
\hline High & 1933(32.4) & $1690(34.3)$ & \\
\hline Smoking , $n(\%)$ & & & $<0.001$ \\
\hline Ever/Never & $5870(98.4)$ & $2155(43.7 \%)$ & \\
\hline Current & $94(1.6)$ & $2779(56.3 \%)$ & \\
\hline Drinking , $n(\%)$ & & & $<0.001$ \\
\hline Ever/Never & $5563(93.3)$ & 2153(43.6) & \\
\hline Current & $401(6.7)$ & 2781(56.4) & \\
\hline BMI category, $n(\%)$ & & & $<0.001$ \\
\hline Thin & 291(4.9) & 183(3.7) & \\
\hline Normal & 2931(49.1) & $2220(45.0)$ & \\
\hline Overweight & 1933(32.4) & $1820(36.9)$ & \\
\hline Obesity & $809(13.6)$ & $711(14.4)$ & \\
\hline BMI $\left(\mathrm{kg} / \mathrm{m}^{2}\right)$ & $24.0 \pm 0.1$ & $24.4 \pm 0.1$ & $<0.001$ \\
\hline $\mathrm{WC}(\mathrm{cm})$ & $81.0 \pm 0.2$ & $86.2 \pm 0.2$ & $<0.001$ \\
\hline \multicolumn{4}{|l|}{ Dietary intake } \\
\hline Daily energy (k cal) & $1919.4 \pm 8.9$ & $2273.9 \pm 11.3$ & $<0.001$ \\
\hline Fat $(g)$ & $77.7 \pm 0.6$ & $91.5 \pm 0.7$ & $<0.001$ \\
\hline Protein $(g)$ & $62.3 \pm 0.3$ & $74.0 \pm 0.4$ & $<0.001$ \\
\hline Carbohydrate (g) & $242.0 \pm 1.4$ & $282.4 \pm 1.8$ & $<0.001$ \\
\hline Fat $\left(\% E^{3}\right)$ & $35.9 \pm 0.2$ & $36.0 \pm 0.2$ & 0.819 \\
\hline Protein (\% E $\left.{ }^{4}\right)$ & $13.2 \pm 0.1$ & $13.2 \pm 0.1$ & 0.197 \\
\hline Carbohydrate $\left(\% \mathrm{E}^{5}\right)$ & $50.7 \pm 0.2$ & $49.8 \pm 0.2$ & $<0.001$ \\
\hline
\end{tabular}

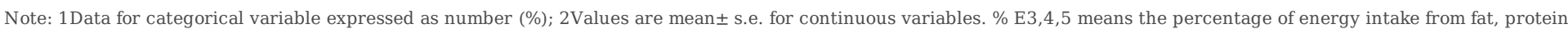
and carbohydrate, respectively.

\section{Dietary intake by social demographic characteristics}

The distribution of dietary intake by social demographic characteristics in different genders were presented in Table 2 . There were significant differences in the dietary energy intake between different income levels and PA groups in females ( $p<0.001$ ), and between different geogerphical regions and PA groups in males $(\mathrm{p}<0.001)$. Participants with the highest income had the most dietary fat intake regardless of gender (94.9 $\mathrm{g}$ in males and $80.5 \mathrm{~g}$ in females; p < 0.001). Females aged 18-44 years (62.5 g) had more dietary protein intake than females aged 45-64 years $(61.8 \mathrm{~g})$ ( $\mathrm{p}<0.001)$. Additionally, there were significant differences in dietary protein intake among different education levels, income levels, and geogerphical regions regardless of gender $(\mathrm{p}<0.001)$. Urban males had the highest protein intake of $77.4 \mathrm{~g}$. Dietary carbohydrate intake varied significantly across social demographic characteristics.The highest levels of PA had the most carbohydrate intake regardless of gender (296.3 $\mathrm{g}$ in males and $256.6 \mathrm{~g}$ in females; $\mathrm{p}<0.001$ ).

$<$ Table $2>$ Distribution of dieatry energy intake and macronutrient composition

There were significant differences in the distribution of dietary energy from macronutrients as per BMI categories by sex differentiation (Table 3). Males showed greater absolute intakes of dietary energy and macronutrients as compared to females in the BMI categories comparison $(\mathrm{p}<0.001)$. In the normal BMI category, the percentage of dieary energy intake from carbohydrate in females $(50.7 \%)$ was significantly higher than that in males $(49.9 \%)(p<0.001)$. In the overweight BMI category, the percentage of dieatry energy intake from 
carbohydrates in females (50.6\%) was significantly higher than that in males (49.5\%), while the percentage of dietary energy intake from proteins in females $(13.1 \%)$ was significantly lower than that in males $(13.4 \%)(p<0.001)$.

$<$ Table 3 > Energy and macronutrients consumption in different weight outcomes by sex

Table 2 The distribution of daily energy and macronutrient intake by social-demographic characteristics in $2015^{1,2}$

\begin{tabular}{|c|c|c|c|c|c|c|c|c|}
\hline \multirow{2}{*}{$\begin{array}{l}\text { General } \\
\text { Characteristic }\end{array}$} & \multicolumn{4}{|c|}{ Women $(\mathrm{N}=5,964)$} & \multicolumn{4}{|c|}{$\operatorname{Men}(\mathrm{N}=4,934)$} \\
\hline & Energy (k cal) & Fat(g) & Protein $(\mathrm{g})$ & Carbohydrate(g) & Energy (k cal) & Fat(g) & Protein(g) & $\begin{array}{c}\text { Carbohydrate } \\
\text { (g) }\end{array}$ \\
\hline \multicolumn{9}{|l|}{ Age } \\
\hline 18-44 years & $1931.4 \pm 14.5$ & $77.8 \pm 0.9$ & $62.5 \pm 0.5^{* *}$ & $244.5 \pm 2.2^{*}$ & $2300.6 \pm 19.5$ & $91.8 \pm 1.2$ & $74.7 \pm 0.7$ & $290.8 \pm 3.2^{* * *}$ \\
\hline 45-64 years & $1911.7 \pm 11.3$ & $77.7 \pm 0.7$ & $61.8 \pm 0.4$ & $240.4 \pm 1.7$ & $2259.2 \pm 13.9$ & $91.3 \pm 0.9$ & $73.6 \pm 0.5$ & $277.7 \pm 2.1$ \\
\hline \multicolumn{9}{|l|}{ Education level } \\
\hline Primary/illiterate & $1915.3 \pm 16.4$ & $76.5 \pm 1.0$ & $59.0 \pm 0.6^{* * *}$ & $246.9 \pm 2.6^{* * *}$ & $2258.7 \pm 26.2$ & $90.8 \pm 1.6$ & \multirow{2}{*}{$\begin{array}{c}69.2 \pm 0.9^{* * *} \\
73.6 \pm 0.7\end{array}$} & $283.5 \pm 4.3^{\text {*** }}$ \\
\hline Middle school & $1938.8 \pm 15.6$ & $77.3 \pm 1.0$ & $61.5 \pm 0.6$ & $248.4 \pm 2.5$ & $2297.1 \pm 19.1$ & $91.1 \pm 1.1$ & & $288.5 \pm 3.0$ \\
\hline High/above & $1903.0 \pm 14.5$ & $79.2 \pm 0.6$ & $65.4 \pm 0.6$ & $231.3 \pm 2.0$ & $2259.1 \pm 16.5$ & $92.1 \pm 1.4$ & $76.6 \pm 0.6$ & $276.1 \pm 2.5$ \\
\hline \multicolumn{9}{|l|}{ Income level } \\
\hline Low & $1964.4 \pm 17.4^{* * *}$ & $78.8 \pm 1.1^{* * *}$ & $60.8 \pm 0.6^{* * *}$ & $251.9 \pm 2.7^{* * *}$ & $2300.9 \pm 22.4$ & \multirow{2}{*}{$\begin{array}{c}90.9 \pm 1.3^{* * *} \\
88.1 \pm 1.2\end{array}$} & \multirow{2}{*}{$\begin{array}{c}71.4 \pm 0.7^{* * *} \\
72.4 \pm 0.7\end{array}$} & $293.4 \pm 3.7^{\text {*** }}$ \\
\hline Medium & $1894.7 \pm 15.0$ & $73.7 \pm 0.9$ & $60.4 \pm 0.5$ & $246.6 \pm 2.5$ & $2260.3 \pm 19.7$ & & & $287.7 \pm 3.2$ \\
\hline High & $1903.1 \pm 14.1$ & $80.5 \pm 1.0$ & $64.8 \pm 0.5$ & $228.9 \pm 2.0$ & $2265.1 \pm 17.5$ & $94.9 \pm 1.1$ & $77.4 \pm 0.7$ & $269.3 \pm 2.5$ \\
\hline \multicolumn{9}{|c|}{ Geogerphical region } \\
\hline Rural & $1914.9 \pm 11.3$ & $74.9 \pm 0.7^{* * *}$ & $59.9 \pm 0.4^{* * *}$ & $249.4 \pm 1.8^{* * *}$ & $2295.2 \pm 14.5^{* *}$ & \multirow{2}{*}{$\begin{array}{c}90.4 \pm 0.9^{* * *} \\
93.3 \pm 1.1\end{array}$} & \multirow{2}{*}{$\begin{array}{c}72.4 \pm 0.5^{* * *} \\
76.8 \pm 0.7\end{array}$} & $290.9 \pm 2.3^{* * *}$ \\
\hline Urban & $1927.0 \pm 14.6$ & $82.4 \pm 1.0$ & $65.8 \pm 0.6$ & $229.6 \pm 2.0$ & $2237.2 \pm 18.0$ & & & $267.6 \pm 2.7$ \\
\hline \multicolumn{9}{|l|}{ PA level } \\
\hline Low & $1892.7 \pm 16.0^{* * *}$ & $77.8 \pm 1.1$ & $61.9 \pm 0.6$ & $235.4 \pm 2.4^{* * *}$ & $2258.8 \pm 19.8^{* * *}$ & $91.7 \pm 1.2$ & $73.7 \pm 0.7$ & $279.0 \pm 3.0^{* * *}$ \\
\hline Medium & $1890.9 \pm 14.4$ & $77.7 \pm 0.9$ & $62.3 \pm 0.5$ & $234.6 \pm 2.2$ & $2221.8 \pm 18.8$ & $90.8 \pm 1.1$ & $74.3 \pm 0.7$ & $270.7 \pm 3.0$ \\
\hline High & $1976.9 \pm 16.0$ & $77.5 \pm 1.0$ & $62.1 \pm 0.6$ & $256.6 \pm 2.6$ & $2336.4 \pm 20.0$ & $91.9 \pm 1.2$ & $74.0 \pm 0.7$ & $296.3 \pm 3.2$ \\
\hline
\end{tabular}

Note: 1 Values are mean \pm s.e. for continuous variables .2 ***, ** and * indicate statistical significance at the $1 \%, 5 \%$ and $10 \%$ level, respectively.

Table 3 Dietary energy and macronutrient intake among different BMI categories by gender in 2015

\begin{tabular}{|c|c|c|c|c|c|c|c|c|}
\hline \multirow{2}{*}{$\begin{array}{l}\text { Dietary } \\
\text { intake }\end{array}$} & \multicolumn{2}{|c|}{ The thin BMI category } & \multicolumn{2}{|c|}{ The normal BMI category } & \multicolumn{2}{|c|}{ The overweight BMI category } & \multicolumn{2}{|c|}{ The obesity BMI } \\
\hline & $\begin{array}{l}\text { Women } \\
\square N=291 \square\end{array}$ & $\begin{array}{c}\text { Men } \\
\square N=183 \square \\
\end{array}$ & $\begin{array}{c}\text { Women } \\
\square N=2931 \square\end{array}$ & $\begin{array}{c}\text { Men } \\
\square N=2220 \square \\
\end{array}$ & $\begin{array}{c}\text { Women } \\
\square N=1933 \square\end{array}$ & $\begin{array}{c}\text { Men } \\
\square \mathrm{N}=1820 \square \\
\end{array}$ & $\begin{array}{c}\text { Women } \\
\square \mathrm{N}=809 \square\end{array}$ & \\
\hline $\begin{array}{l}\text { Energy } \\
\text { (k cal) }\end{array}$ & $1887.7 \pm 40.0$ & $2296.8 \pm 65.7^{* * *}$ & $1908.0 \pm 12.7$ & $2234.7 \pm 16.8^{* * *}$ & $1948.2 \pm 16.1$ & $2290.3 \pm 18.4^{* * *}$ & $1903.2 \pm 23.1$ & 234 \\
\hline $\begin{array}{l}\text { Fat } \\
(g)\end{array}$ & $76.8 \pm 2.7$ & $92.4 \pm 4.1^{* * *}$ & $77.0 \pm 0.8$ & $90.0 \pm 1.1^{* * *}$ & $79.0 \pm 1.0$ & $92.4 \pm 1.1^{* * *}$ & $77.4 \pm 1.6$ & 93. \\
\hline $\begin{array}{l}\text { Protein } \\
\text { (g) }\end{array}$ & $60.6 \pm 1.4$ & $71.4 \pm 2.1^{* * *}$ & $62.1 \pm 0.5$ & $72.2 \pm 0.6^{* * *}$ & $62.9 \pm 0.6$ & $75.5 \pm 0.7^{* * *}$ & $60.7 \pm 0.8$ & 76. \\
\hline $\begin{array}{l}\text { Carbohydrate } \\
\text { (g) }\end{array}$ & $237.9 \pm 6.0$ & $290.0 \pm 10.3^{* * *}$ & $240.5 \pm 1.9$ & $277.7 \pm 2.6^{* * *}$ & $245.0 \pm 2.5$ & $282.6 \pm 2.9^{* * *}$ & $240.1 \pm 3.4$ & 294 \\
\hline $\begin{array}{l}\text { Fat } \\
\left(\% E^{3}\right)\end{array}$ & $35.9 \pm 0.7$ & $36.1 \pm 1.0$ & $35.8 \pm 0.2$ & $35.9 \pm 0.3$ & $36.1 \pm 0.3$ & $36.1 \pm 0.3$ & $35.9 \pm 0.4$ & 35. \\
\hline $\begin{array}{l}\text { Protein } \\
\left(\% E^{4}\right)\end{array}$ & $13.0 \pm 0.2$ & $12.8 \pm 0.2$ & $13.3 \pm 0.1$ & $13.2 \pm 0.1$ & $13.1 \pm 0.1$ & $13.4 \pm 0.1^{* *}$ & $13.2 \pm 0.1$ & 13. \\
\hline $\begin{array}{l}\text { Carbohydrate } \\
\left(\% \mathrm{E}^{5}\right)\end{array}$ & $50.9 \pm 0.7$ & $50.4 \pm 1.0$ & $50.7 \pm 0.2$ & $49.9 \pm 0.3^{* *}$ & $50.6 \pm 0.3$ & $49.5 \pm 0.3^{* *}$ & $51.0 \pm 0.4$ & 50. \\
\hline
\end{tabular}

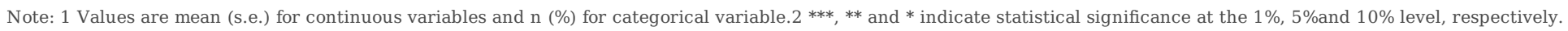
$\% \mathrm{E} 3,4,5$ means the percentage of energy intake from fat, protein and carbohydrate, respectively.

Figure 1a shows a significant difference in the percentage of dietary energy intake from fat between males and females within the DRIs recommended range (20-30\%). Females in the underweight, overweight, obesity BMI categories, and abdominal obesity groups had significantly higher percentage of dietary energy intake from fat than males, in line with the DRIs (20-30\%) ( $p<0.001)$. Moreover, with weight gain in females, the percentage of dietary energy intake from fat was significantly lower than the DRIs recommended range (20$30 \%)(\mathrm{p}<0.001)$. The proportion of percentage of dietary energy intake from fat over the DRIs standard ( $>30 \%)$ was significantly 
different between males and females (Figure 1b). Specifically, in the underweight and the normal BMI category, females who exceeded the DRI standard (>30\%) was significantly more than that of males, as opposed to the overweight/obese BMI categories and abdominal obesity groups $(\mathrm{p}<0.001)$. There was a significant difference in males and females with respect to the percentage of dietary energy intake from carbohydrates in line with the DRIs standard (50-65\%) (Figure 1c). Females in the normal, overweight and obesity BMI categories, and the abdominal obesity groups had significantly higher percentage of dietary energy intake from carbohydrates than males, in line with the DRIs (50-65\%), as opposed to the underweight group. Figure 1c suggested that the proportion of the percentage of dietary energy intake from carbohydrates below the recommended DRIs $(<50 \%)$ increased significantly with weight gain $(\mathrm{p}<0.001)$. Furthermore, males below the recommended DIRs (<50\%) (Figure 1d) were significantly more than that of females in the normal, overweight and obesity BMI categories, and abdominal obesity groups, as opposed to the underweight group (p < 0.001 ).

Figure 1. Dietary energy intake from fat and carbohydrate compared with the DRIs standard in subgroups with different weight outcomes

$<$ Figure 1a > The proportion of dietary energy intake from fat within the recommended values (20-30\%) among body weight outcomes by sex

$<$ Figure $1 \mathrm{~b}>$ the proportion of dietary energy intake from fat beyond the recommended values (>30\%) among body weight outcomes by $\operatorname{sex}$

$<$ Figure 1c > the proportion of dietary energy intake from carbohydrate within the recommended values (50-65\%) among body weight outcomes by sex

$<$ Figure $1 \mathrm{~d}>$ the proportion of dietary energy intake from carbohydrate below the recommended values $(<50 \%)$ among body weight outcomes by sex

As shown in Table 4, the associations between dietary energy and macronutrient consumption and BMI were estimated using quantile regressions. From the adjusted model for males, significant coefficients for BMI were observed at the 25 th, 50 th, 75 th, and 95 th dietary energy quantiles $(\mathrm{p}<0.05)$, at the 75th and 95 th dietary fat quantiles $(\mathrm{p}<0.05)$, at the 5 th, 25 th, 50 th, and 75 th dietary protein quantiles $(\mathrm{p}<0.05)$, and at the 75th and 95th dietary carbohydrate quantiles $(\mathrm{p}<0.05)$. Furthermore, the increase in dietary energy and fat intake was higher at the upper end of the distribution, suggesting that males with higher BMI had an additional dietary energy and fat intake than individuals with lower BMI. Moreover, a 10\% increase in BMI lead to an additional intake of 0.002-0.004 $\mathrm{kcal} / \mathrm{d}$ of dietary energy, 0.032-0.057 g/d of dietary fat, 0.039-0.084 g/d of dietary protein, and 0.018-0.028 g/d of dietary carbohydrate across all quantiles in males $(\mathrm{p}<0.05)$.

$<$ Table $4>$ Associations between dietary energy, macronutrient intakes and BMI

With respect to our findings stated in Table 5, significant coefficients for WC in males were observed at the 75th and 95th dietary energy quantiles ( $\mathrm{p}<0.05)$ and at the 75 th and 95 th dietary protein quantiles $(\mathrm{p}<0.05)$, whereas, in females, the statistically coefficients were observed at the 25 th and 50 th quantiles dietary carbohydrate quantiles ( $\mathrm{p}<0.05$ ). A $10 \%$ increase in WC lead to an additional intake of 0.004-0.008 kcal/d of dietary energy and 0.051-0.052 g/d of dietary carbohydrates across all quantiles in males (p < 0.05), and 0.060$0.150 \mathrm{kcal} / \mathrm{d}$ of dietary fat in females $(\mathrm{p}<0.05)$. On the other hand, a $10 \%$ increase in WC lead to a reduced intake of $0.051-0.052 \mathrm{~g} / \mathrm{d}$ of dietary carbohydrate across all quantiles in females $(\mathrm{p}<0.05)$.

$<$ Table $5>$ Associations between dietary energy, macronutrient intakes and WC 
Table4 Quantile regression estimates for the association between energy intake and macronutrient composition and BMI (kg/m ${ }^{2}$ ) in

CHNS 2015 $1,2,3$

\begin{tabular}{|c|c|c|c|c|c|c|c|c|c|c|c|}
\hline \multirow[t]{2}{*}{ Dietary intake } & & \multicolumn{5}{|c|}{ MEN } & \multicolumn{5}{|c|}{ WOMEN } \\
\hline & & 5th & 25th & 50th & 75th & 95th & 5 th & 25th & 50th & 75th & 95th \\
\hline \multirow[t]{2}{*}{ Energy (kcal) } & $\begin{array}{l}\text { Model } \\
1\end{array}$ & 0.0001 & $0.0001^{*}$ & $0.0025^{* *}$ & $0.0026^{* * *}$ & $0.0046^{* * *}$ & 0.0001 & 0.0001 & 0.0001 & -0.0001 & 0.0001 \\
\hline & $\begin{array}{l}\text { Model } \\
2\end{array}$ & 0.0001 & $0.0002^{* *}$ & $0.0003^{* *}$ & $0.0004^{* * *}$ & $0.0004^{* *}$ & 0.0001 & 0.0001 & 0.0001 & 0.0001 & -0.0001 \\
\hline \multirow[t]{2}{*}{ Fat (g) } & $\begin{array}{l}\text { Model } \\
1\end{array}$ & 0.0023 & 0.0016 & 0.0031 & 0.0025 & $0.0049^{* * *}$ & 0.0009 & 0.0014 & 0.0014 & -0.0017 & -0.0007 \\
\hline & $\begin{array}{l}\text { Model } \\
2\end{array}$ & 0.0030 & 0.0020 & 0.0022 & $0.0032^{* * *}$ & $0.0057^{* * *}$ & 0.0021 & 0.0010 & 0.0010 & 0.0006 & -0.0035 \\
\hline \multirow[t]{2}{*}{ Protein (g) } & $\begin{array}{l}\text { Model } \\
1\end{array}$ & $0.0056^{*}$ & $0.0100^{* * *}$ & $0.0107^{* * *}$ & $0.0085^{* * *}$ & 0.0088 & 0.0033 & 0.0022 & 0.0016 & -0.0044 & -0.0056 \\
\hline & $\begin{array}{l}\text { Model } \\
2\end{array}$ & $0.0039^{* *}$ & $0.0059^{* *}$ & $0.0086^{* * *}$ & $0.0084^{* * *}$ & 0.0081 & 0.0031 & 0.0027 & 0.0025 & -0.0001 & -0.0001 \\
\hline \multirow[t]{2}{*}{ Carbohydrate (g) } & $\begin{array}{l}\text { Model } \\
1\end{array}$ & -0.0003 & 0.0004 & $0.0009^{* * *}$ & $0.0013^{* * *}$ & $0.0025^{* *}$ & 0.0002 & 0.0005 & 0.0007 & -0.0005 & -0.0003 \\
\hline & $\begin{array}{l}\text { Model } \\
2\end{array}$ & 0.0001 & 0.0009 & $0.0016^{*}$ & $0.0018^{* *}$ & $0.0028^{* * *}$ & 0.0003 & 0.0007 & 0.0001 & 0.0004 & -0.0001 \\
\hline \multirow[t]{2}{*}{ Fat $\left(\% E^{4}\right)$} & $\begin{array}{l}\text { Model } \\
1\end{array}$ & 0.0009 & 0.0005 & 0.0013 & 0.0020 & -0.0099 & 0.0001 & 0.0001 & 0.0030 & -0.0020 & -0.0021 \\
\hline & $\begin{array}{l}\text { Model } \\
2\end{array}$ & 0.0015 & 0.0006 & 0.0039 & 0.0022 & 0.0133 & 0.0071 & -0.0003 & 0.0044 & -0.0015 & -0.0150 \\
\hline \multirow[t]{2}{*}{ Protein $\left(\% E^{5}\right)$} & $\begin{array}{l}\text { Model } \\
1\end{array}$ & $0.0489^{* *}$ & $0.0565^{* * *}$ & $0.0427^{* *}$ & $0.0202^{*}$ & $-0.0593^{* *}$ & 0.0155 & -0.0045 & -0.0242 & -0.0410 & -0.0520 \\
\hline & $\begin{array}{l}\text { Model } \\
2\end{array}$ & 0.0256 & 0.0180 & 0.0069 & 0.0172 & -0.0623 & 0.020 & 0.0156 & 0.0060 & -0.0160 & -0.0373 \\
\hline \multirow[t]{2}{*}{$\begin{array}{l}\text { Carbohydrate(\% } \\
\left.E^{6}\right)\end{array}$} & $\begin{array}{l}\text { Model } \\
1\end{array}$ & -0.0152 & -0.0043 & -0.0024 & 0.0014 & 0.0028 & -0.0040 & -0.0010 & -0.0005 & 0.0043 & 0.0042 \\
\hline & $\begin{array}{l}\text { Model } \\
2\end{array}$ & -0.0019 & 0.0007 & 0.0040 & 0.0024 & 0.0173 & -0.0066 & 0.0003 & -0.0050 & 0.0036 & 0.0164 \\
\hline
\end{tabular}

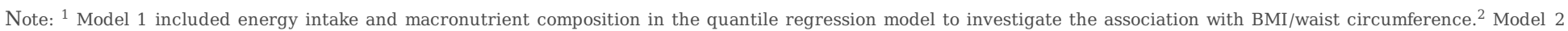

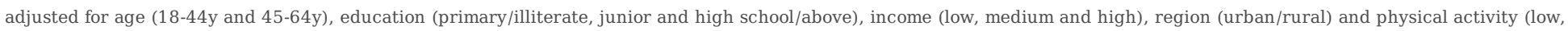

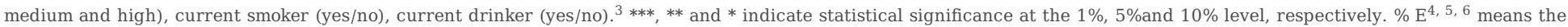
percentage of energy intake from fat, protein and carbohydrate, respectively.

Table 5 Quantile regression estimates for the association between energy intake and macronutrient composition and WC(cm) in CHNS 2015 $1,2,3$

\begin{tabular}{lccccccccccccc}
\hline Dietary intake & & \multicolumn{4}{c}{ MEN } & \multicolumn{4}{c}{ WOMEN } \\
\cline { 2 - 10 } & & 5th & 25th & 50th & 75th & 95th & 5th & 25th & 50th & 75th & 95th \\
\hline Energy (kcal) & Model 1 & -0.0008 & -0.0001 & 0.0005 & $0.0007^{* *}$ & $0.0011^{* *}$ & -0.0012 & -0.0001 & -0.0001 & -0.0005 & -0.0004 \\
& Model 2 & -0.0006 & $0.0004^{*}$ & $0.0004^{*}$ & $0.0007^{* *}$ & $0.0008^{* *}$ & -0.0014 & -0.0001 & -0.0002 & -0.0003 & -0.0001 \\
Fat (g) & Model 1 & -0.0103 & $0.0056^{*}$ & $0.0086^{* *}$ & 0.0041 & 0.0062 & -0.0190 & 0.0010 & 0.0001 & 0.0072 & 0.0140 \\
& Model 2 & -0.0027 & 0.0082 & 0.0041 & 0.0050 & 0.0045 & -0.0117 & 0.0001 & 0.0005 & $0.0060^{*}$ & $0.0150^{* *}$ \\
Protein (g) & Model 1 & -0.0200 & $0.0139^{* *}$ & $0.0194^{* * *}$ & $0.0170^{* *}$ & 0.0238 & -0.0500 & -0.0166 & -0.0061 & -0.0189 & -0.0217 \\
& Model 2 & -0.0238 & 0.0107 & 0.0105 & 0.0131 & 0.0252 & -0.0385 & 0.0001 & -0.0084 & -0.0108 & -0.0098 \\
Carbohydrate (g) & Model 1 & -0.0044 & -0.0001 & -0.0001 & $0.0042^{*}$ & $0.0064^{*}$ & -0.0061 & -0.0007 & -0.0001 & -0.0006 & 0.0034 \\
& Model 2 & -0.0049 & 0.0009 & 0.0023 & $0.0052^{* *}$ & $0.0051^{* *}$ & -0.0085 & $-0.0001^{* *}$ & $-0.0023^{* *}$ & 0.0001 & 0.0045 \\
Fat (\% E ${ }^{4}$ ) & Model 1 & 0.0226 & 0.0001 & 0.0001 & 0.0236 & -0.0308 & 0.0265 & 0.0050 & 0.0001 & -0.0300 & -0.0515 \\
& Model 2 & 0.0080 & 0.0069 & 0.0027 & 0.0374 & -0.0323 & 0.0257 & 0.0001 & 0.0126 & -0.0269 & -0.0896 \\
Protein (\% E5) & Model 1 & 0.1543 & 0.0714 & 0.0960 & 0.0001 & 0.0810 & -0.1222 & -0.0974 & -0.066 & -0.103 & -0.136 \\
& Model 2 & 0.0367 & 0.0307 & -0.0335 & -0.0778 & 0.0235 & 0.0001 & 0.0001 & -0.0246 & 0.0001 & -0.075 \\
Carbohydrate(\% E ${ }^{6}$ ) & Model 1 & -0.0195 & -0.0001 & -0.0161 & 0.0211 & 0.0001 & -0.0226 & -0.0021 & -0.0001 & 0.0414 & 0.0614 \\
& Model 2 & -0.0172 & -0.0020 & 0.0111 & 0.0364 & 0.0267 & -0.0302 & -0.0001 & -0.0115 & 0.0302 & 0.0897 \\
\hline
\end{tabular}

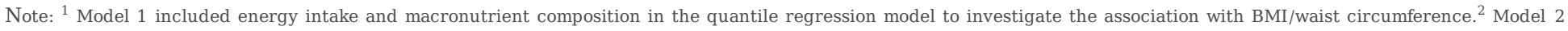

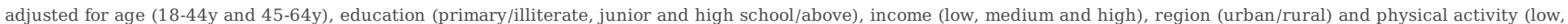

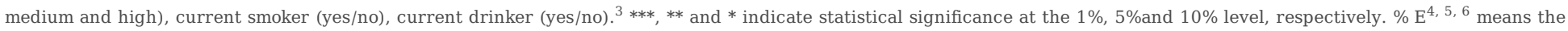
percentage of energy intake from fat, protein and carbohydrate, respectively.

\section{Discussion}

It is an effort to assess the latest nutritional status concentrating on the socioeconomic status and body weight outcomes. Additionally, the present study provided more evidences on sex disparities with respect to the associations between energy and macronutrient intakes and body weight outcomes in Chinese adults. Both developed and developing countries had reported sex-related differences in obesity[21, 22]. Research by the Institute for Health Metrics and Evaluation demonstrated that adult females are consistently more obese than males in developing countries, possibly due to different roles, social status, and 
gender-norms in the family. Additionally, a study of sex-related differences of obesity-related alterations in intrinsic brain activity showed a stronger relationship between increased BMI and decreased connectivity of core reward network components with cortical and emotional regulation regions in females, which could be related to the greater prevalence of emotional eating [23]. Therefore, it is important to consider individual sex differences to prevent and treat obesity. Our study report sex-related disparities in energy and macronutrients intake. Significant relationships were found between dietary energy intake and different income levels just in females, which illustrated that socioeconomic factors possibly induced different effects on males and females. Income was reported as an important factor to affect the dietary structure of adults in China in a previous study, which possibility influenced the purchasing power and determined the choice of food of the residents[24].This creates cost and accessibility barriers for healthy food choices for low-income individuals[25].Our study specifically found that females with low income had the highest dietary energy intake. Therefore, it is important to guide them to conduct reasonable energy consumption. Both western countries and China had investigated the interactions between PA and obesity risk across sexes. Rashad found that leisure time PA had a negative impact on BMI, and the effect was more pronounced in females, using nationally representative longitudinal data from Canada's National Population Health Survey[26]. Hongqiu Gu evaluated the PA patterns of urban and rural dwellers in China and found that urban males were less physically active than rural males and had a higher prevalence of obesity in the study involving Chinese[27]. Our study reported that rural adult with high PA consumed more dietary energy, possibly due to higher energy expenditure from outdoor activities and agricultural work[28]. Additionally, from the adjusted quantile regression model, it was reported that more dietary energy intake had positive effects on the BMI and WC in males, indicating that obese male may need more energy to maintain weight. Results from the World Health Organization Multinational Monitoring of Trends and Determinants in Cardiovascular Disease aggregate level analyses further supported this positive correlation between dietary energy intake and weight status in European countries[29].

The role of dietary fat as a major determinant of obesity was not without controversy, but was better established[30]. Notably, urban residents with higher income tended to consume more dietary fat, and this was supported by previous studies reporting a positive link between fat intake, economic growth, and nutrition transitions globally in the past several decades[31]. Our study reported that more dietary fat intake had positive effects on the higher distribution of BMI (in males) and WC (in females), which implied that dietary fat could increase the risk of general obesity in males and abdominal obesity in females. A cohort study from the National Health and Nutrition Examination Survey found that the percentage of dietary energy intake from fat and weight changes were inversely related in females, but positively associated in males without any morbidity[32]. In the present study, we found that that high-fat diets are associated with greater relative body weight in adults, which was consistent with a previous meta-analysis [33]. The effect of dietary carbohydrates in weight loss had received considerable attention in light of the current obesity epidemic[34]. Researches over the last decade reported that low-carbohydrate diets were a viable option in the treatment of obesity, but its long-term effect (12 months) remained controversial[35]. Our results reported that in most socio-demographic indicators, particularly those of low socioeconomic status groups, males consumed significantly more carbohydrates than females. Previous studies had reported that low-income groups consumed more cereals and lesser fish, meat, vegetables, and fruits than high-income groups, leading to high intake of carbohydrate and lower intake of protein, fat, potassium, and vitamins. Furthermore, food shoppers with low levels of education and income were least likely to purchase foods that were comparatively higher in fiber and lower in fat[36]. Our studies also indicated that the association between carbohydrate intake and body weight outcomes showed higher magnitude in the upper tail of the BMI and WC distribution in Chinese males. Previous research reported that carbohydrates could promote the development of small intestinal bacterial overgrowth in obesity. Meanwhile, certain carbohydrate types could be related to body weight outcomes, because carbohydrates have been traditionally classified as simple or complex on the basis of their chemical structure. Further researches are needed to deepen the understanding of the relationship between dietary carbohydrate types and body weight outcomes. In the present study, urban residents with high socioeconomic status consumed more proteins. Meanwhile, the association between dietary protein and body weight outcomes showed higher magnitude in the BMI distribution, consistent with a systematic review and meta-analysis that was conducted to assess the benefits and drawbacks of high-protein diets as compared to low-protein diets, and showed that higher-protein diets probably improved adiposity[37]. The Chinese dietary guideline (CDG) version of 2016 for Chinese adults suggested the dietary energy intake from fat, carbohydrate, and protein were below $30 \%$, $55-65 \%$, and 10 $15 \%$, respectively. Compared with the CDG recommendations, the proportion of dietary energy intake from protein was found to be in line with the CDG recommendations, while carbohydrates were below the recommendations and fats exceeded the recommendations. Moreover, the percentage of overweight/obese people deriving the percentage of dietary energy intake from fat was more than $30 \%$, which was significantly higher than those of normalweight people. Moreover, the association between the percentage of dietary energy intake from fat, protein, carbohydrate and body weight outcomes were not found, which was similar to the study results conducted in Australian children and adolescents[38].

\section{Strengths and Limitations}

The present study had certain strengths. First, we used updated data to observe the distribution of dietary energy and macronutrient intake in the largest developing country, which provided the latest nutritional status of Chinese residents. Second, the sample size was large with a wide age range, and the staff was trained in the study's methodology and standardization in different parameters at the same time by the same scientists. However, there were several limitations. First, this study was subject to the same limitations that affect all cross-sectional analysis, including possible reverse causality, therefore, extrapolated conclusion should be made cautiously. Second, dietary data were collected using three consecutive 24-h dietary recalls, which might show relatively limited variations for a participant as compared to non-consecutive $24-\mathrm{h}$ recalls. However, the average intake over three days could offer a relatively valid estimate of nutrient intake, as shown in an earlier study using the CHNS data.

\section{Conclusions}

Chinese adults tend to have a high-fat and low-carbohydrate diet. Excessive intake of dietary fat could be risk factors of abdominal obesity among Chinese females. Health professionals should consider the weight of evidence before promoting one form of macronutrient distribution over another to prevent and treat obesity in different gender groups.

\section{List Of Abbreviations}


CHNS: China Health and Nutrition Survey; BMI: Body mass index; WC: Waist circumference; QR: Quantile regression; CDC: Centers for Disease Control and Prevention; MET: metabolic equivalents of task; WHO: World Health Organization; CDG: Chinese dietary guideline; SD: Standard deviation; DRI: Dietary Reference Intake; MET: Metabolic Equivalent of Task; PA: Physical Activity

\section{Declarations}

Ethics approval and consent to participate

The study was approved by the Institutional Review Boards of the University of North Carolina at Chapel Hill and the National Institute for Nutrition and Health, Chinese Center for Disease Control and Prevention. Each participant provided written informed consent (No. 201524).

\section{Consent for publication}

Not applicable

\section{Availability of data and material}

The datasets used and analysed during the current study are available from the corresponding author on reasonable request.

\section{Funding}

This work was supported by the National Key R\&D program of China (2019YFC1605100), the Carolina Population Center (5 R24 HD050924), University of North Carolina at Chapel Hill, the National Institutes of Health (NIH) (R01-HD30880, DK056350, and R01-HD38700), and the Fogarty International Center, NIH (5D43TW007709 and 5D43TW009077) for the CHNS data collection and analysis files from 1989 to 2015 and future surveys.

\section{Acknowledgement}

The authors thank the team at the National Institute for Nutrition and Health, Chinese Center for Disease Control and Prevention and the Carolina Population Center, University of North Carolina at Chapel Hill. The authors are also grateful to the participants for their involvement in the survey.

\section{Authors' Contributions}

All authors contributed significantly to this article. JZ performed the analysis, interpreted the data and drafted the manuscript, JS critically revised the manuscript for important intellectual content. SC conceived and designed the study. All authors read, provide major revisions and approved the final submitted version of the manuscript.

\section{Competing Interests}

The authors have no conflict of interest to declare

\section{Authors' Information}

1.Institute of Basic Medical Sciences, Chinese Academy of Medical Sciences / School of Basic Medicine, Peking Union Medical College, Beijing 100005, China

2. School of Public Health \& Management, Ningxia Medical University, Chinese Center for Disease Control and Prevention, Ningxia 750004, China

3. National Institute for Nutrition and Health, Chinese Center for Disease Control and Prevention, Beijing 100050, China.

\section{References}

1. Pereira-Miranda E, Costa P, Queiroz V, Pereira-Santos M, Santana ML: Overweight and Obesity Associated with Higher Depression Prevalence in Adults: A Systematic Review and Meta-Analysis. J Am Coll Nutr 2017, 36:223-233.

2. Stokes A, Ni Y, Preston SH: Prevalence and Trends in Lifetime Obesity in the U.S., 1988-2014. AM J PREV MED 2017, 53:S0749379717303100.

3. Zhou L, Zeng Q, Jin S, Cheng G: The impact of changes in dietary knowledge on adult overweight and obesity in China. Plos One 2017, 12:e0179551-.

4. Ness A: Diet, Nutrition and the Prevention of Chronic Diseases. WHO Technical Report Series 916. Report of a Joint WHO/FSA Expert Consultation. $J$ SYMBOLIC LOGIC 2004, 32:188-544.

5. Nelson L, Tucker L: Diet composition related to body fat in a multivariate study of 203 men. J AM DIET ASSOC 1996, 96:771.

6. Peter S, Burg M, Charlie F, Boyd S, Gary S, Mike R, et a: Increased energy intake entirely accounts for increase in body weight in women but not in men in the UK between 1986 and 2000. BRIT J NUTR 2011, 105:1399-1404.

7. Grech A, Rangan A, Allman-Farinelli M: Macronutrient Composition of the Australian Population's Diet; Trends from Three National Nutrition Surveys 1983, 1995 and 2012. Nutrients 2018, 10:1045.

8. Boeing H: Estimating the distribution of usual dietary intake by short-term measurements. EUR J CLIN NUTR 2002, 56:S53.

9. Icl V, Holewijn S, De G, Jhw R: Sex differences in fat distribution influence the association between BMI and arterial stiffness. J HYPERTENS 2017, 35:1219-1225. 
10. Souza A, Barufaldi L, Abreu G, Giannini D, Oliveira C, Santos M, Leal V: ERICA: intake of macro and micronutrients of Brazilian adolescents. Revista De Saúde Pública 2016, 50.

11. Heidari Z, Feizi A, Azadbakht L, Mohammadifard N, Maghroun M, Sarrafzadegan N: Usual energy and macronutrient intakes in a large sample of Iranian middle-aged and elderly populations. NUTR DIET 2018.

12. Xu C, Zhu H, Fang L, Hu R, Wang H, Liang M, et a: Gender disparity in the associations of overweight/obesity with occupational activity, transport to/from work, leisure-time physical activity, and leisure-time spent sitting in working adults: A cross-sectional study. J EPIDEMIOL 2017, 27:401-407.

13. Hu P, Ley S, Bhupathiraju S, Li Y, Wang D: Associations of dietary, lifestyle, and sociodemographic factors with iron status in Chinese adults: a crosssectional study in the China Health and Nutrition Survey. AM J CLIN NUTR 2017, 105:503-512.

14. Zhang B, Zhai F, Du S, Popkin B: The China Health and Nutrition Survey, 1989-2011. OBES REV 2013, 15:2-7.

15. Jiguo Z, Huijun W, Youfa W, Hong X, Zhihong W, Wenwen D, et a: Dietary patterns and their associations with childhood obesity in China. Br J Nutr 2015, 113:1978-1984.

16. Zhao J, Su C, Wang H, Wang Z, Zhan B: New Evidence on the Effect of Medical Insurance on the Obesity Risk of Rural Residents: Findings from the China Health and Nutrition Survey (CHNS, 2004-2011). Int J Environ Res Public Health 2018, 15.

17. Bo Q, Adair L, Plassman B, Carolina B, Edwards L, Popkin B, et a: Dietary Patterns and Cognitive Decline Among Chinese Older Adults. Epidemiology 2015, 26:758-768.

18. Gao F, Wang Z, Shen H, Yang S, Nie B, Zhou Y: Impact of obesity on mortality in patients with diabetes: Meta-analysis of 20 studies including 250,016 patients. J DIABETES INVEST 2017, 9.

19. Won-Sock C, Kon-Hong W, u-Yeon L, Eun-Tae K, Hyuk-Jung K: The Relationship between Obesity and the High Probability of Dementia Based on the Body Mass Index and Waist Circumference. Korean Journal of Family Medicine 2012, 33:17-24.

20. Huang L, Wang H, Wang Z, Zhang J, Zhang B, Ding G: Regional Disparities in the Association between Cereal Consumption and Metabolic Syndrome: Results from the China Health and Nutrition Survey. Nutrients 2019, 11.

21. Wells J, Marphatia A, Cole T, David M: Associations of economic and gender inequality with global obesity prevalence: understanding the female excess. SOC SCI MED 2012, 75:482-490.

22. Plurphanswat N, Rodu B: The association of smoking and demographic characteristics on body mass index and obesity among adults in the U.S., 19992012. Bmc Obes 2014, 1:1-9.

23. Gupta A, Mayer E, Labus J, Bhatt R, Ju T, Love A, et a: Sex Commonalities and Differences in Obesity-Related Alterations in Intrinsic Brain Activity and Connectivity. Obesity (Silver Spring) 2018, 26:340-350.

24. Wang Z, Zhai F, Yuna H, Wang H: Influence of family income on dietary nutrients intake and dietary structure in China. Journal of Hygiene Research 2008, 37:62.

25. Dressler H, Smith C: Food choice, eating behavior, and food liking differs between lean/normal and overweight/obese, low-income women. Appetite 2013, 65:145-152.

26. Sarma S, Zaric G, Campbell M, Gilliland J: The effect of physical activity on adult obesity: Evidence from the Canadian NPHS panel. ECON HUM BIOL 2014, 14:1-21.

27. Gu H, Yang J, Wei L, Teo K, Liu L, Yusuf S: PHYSICAL ACTIVITY AND ITS RELATIONSHIP WITH OBESITY HYPERTENSION AND DIABETES IN URBAN AND RURAL CHINA: THE PURE CHINA STUDY. J AM COLL CARDIOL 2013, 61:E1610-E1610.

28. Lottrup L, Ulrika K, Meilby $\mathrm{H}$, Corazon S: Associations between use, activities and characteristics of the outdoor environment at workplace. URBAN FOR URBAN GREE 2012, 11:159-168.

29. Silventoinen K, Sans S, Tolonen H, Monterde D, Kuulasmaa K, Kesteloot H, et a: Trends in obesity and energy supply in the WHO MONICA Project. Int J Obes Relat Metab Disord 2004, 28:710-718.

30. Bray G, Popkin B: Dietary fat intake does affect obesity! AM J CLIN NUTR 1998, 68:1157-1173.

31. Fernando V, Cecilia A, Juliana K: Nutrition transition in Chile revisited: mid-term evaluation of obesity goals for the period 2000-2010. PUBLIC HEALTH NUTR 2008, 11:405-412.

32. Kant A, Graubard B, Schatzkin A, Ballard-Barbash R: Proportion of energy intake from fat and subsequent weight change in the NHANES I Epidemiologic Follow-up Study. AM J CLIN NUTR 1995, 61:11.

33. Morenga L, Mallard S, Mann J: Dietary sugars and body weight: systematic review and meta-analyses of randomised controlled trials and cohort studies. Bmj Clinical Research 2013, 346:e7492.

34. Yunsheng M, Barbara O, David C, Hebert J, Youfu L, Wenjun L, et a: Association between dietary carbohydrates and body weight. AM J EPIDEMIOL 2005, 161:359.

35. Stem L, Iqbal N, Seshadri P, Chicano K: The effects of low-carbohydrate versus conventional weight loss diets in severely obese adults: One-year follow-up of a randomized trial D. Acc Current Journal Review 2004, 13:778-785.

36. Murayama N: Effects of Socioeconomic Status on Nutrition in Asia and Future Nutrition Policy Studies. J NUTR SCI VITAMINOL 2015, 61 Suppl:S66.

37. Ierardi E, Losurdo G, Sorrentino C, Giorgio F, Rossi G, Marinaro A, et a: Macronutrient intakes in obese subjects with or without small intestinal bacterial overgrowth: an alimentary survey. DIGEST LIVER DIS 2016, 48:e185-186.

38. Elliott S, Truby H, Lee A, Harper C, Abbott R, Davies P: Associations of body mass index and waist circumference with: energy intake and percentage energy from macronutrients, in a cohort of australian children. J NUTR SCI VITAMINOL 2011, 10:58. 
Figures
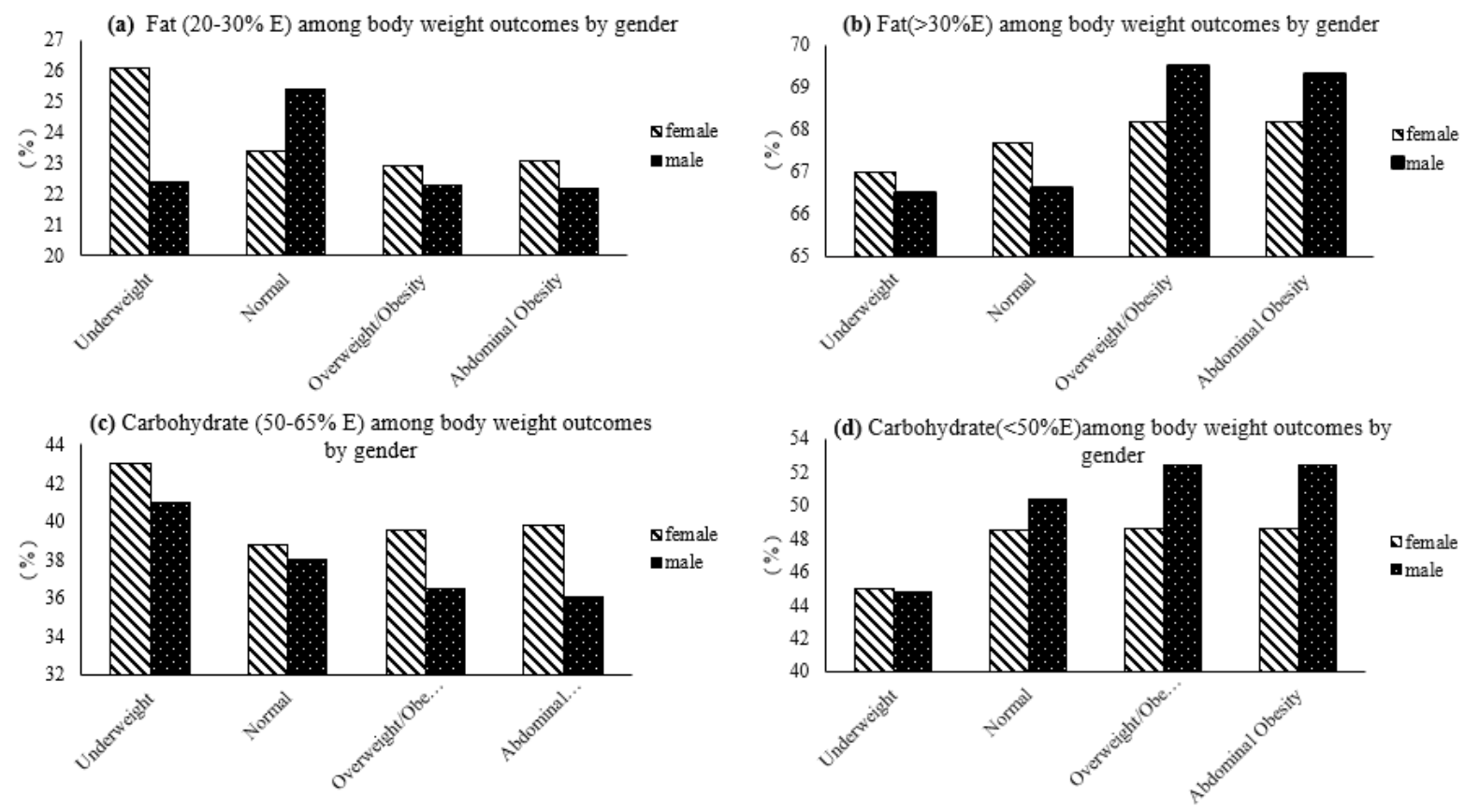

\section{Figure 1}

Dietary energy intake from fat and carbohydrate compared with the DRIs standard in subgroups with different weight outcomes < Figure 1a $>$ The proportion of dietary energy intake from fat within the recommended values (20-30\%) among body weight outcomes by sex < Figure $1 \mathrm{~b}>$ the proportion of dietary energy intake from fat beyond the recommended values $(>30 \%)$ among body weight outcomes by sex < Figure $1 \mathrm{c}>$ the proportion of dietary energy intake from carbohydrate within the recommended values (50-65\%) among body weight outcomes by sex < Figure $1 \mathrm{~d}>$ the proportion of dietary energy intake from carbohydrate below the recommended values $(<50 \%)$ among body weight outcomes by sex 